\title{
NEW TECHNOLOGIES IMPROVING AERODYNAMIC PROPERTIES OF FREIGHT VEHICLES
}

UDC: 629.3 .018 .7

Review paper

https://doi.org/10.18485/aeletters.2019.4.2.2

\author{
Tomas Skrucany ${ }^{1}$, Stefania Semanova ${ }^{1}$, Saša Milojević ${ }^{2}$, Aleksandar Ašonja ${ }^{3,4}$ \\ ${ }^{1}$ Department of Road and Urban Transport, University of Žilina, Slovakia \\ ${ }^{2}$ University of Kragujevac, Faculty of Engineering, Department for Motor Vehicles and IC Engines, Serbia \\ ${ }^{3}$ Energy Agency City of Novi Sad, Novi Sad, Serbia \\ ${ }^{4}$ University Business Academy, Faculty of Economics and Engineering Management, Novi Sad, Serbia
}

\begin{abstract}
:
Fuel consumption of heavy duty vehicles is caused by actual vehicle resistances acting during the vehicle motion. This paper deals with possibilities to reduce the vehicle aerodynamic resistance, air drag coefficient. This resistance effects the vehicle fuel consumption by higher vehicle velocities at most. There are evaluated actual values of vehicle air drag coefficient, possible devices reducing the air drag and the influence of chosen aerodynamic devices on the drag reduction and fuel consumption reduction.
\end{abstract}

\author{
ARTICLE HISTORY \\ Received: 25.04.2019. \\ Accepted: 05.06.2019. \\ Available: 30.06.2019.

\section{KEYWORDS} \\ Aerodynamic devices, air drag \\ reduction, heavy duty vehicles, \\ fuel consumption, drag \\ coefficient
}

\section{INTRODUCTION}

Aerodynamic drag plays an important role in the amount of consumed fuel [1]. The development of the vehicle design is focused on reducing this drag as much as possible and thus to combust less fuel and save money used for fuel purchase as well as to reduce negative impacts on the environment such as noise and emissions. Mainly exhaust gas emissions from vehicles have significant influence on global warming [2-7].

Bodies of heavy-duty vehicles have a higher coefficient of drag than passenger cars due to their dimensions and shape.

The carriers operating heavy-duty vehicles have high costs in the area of fuel consumption either due to high fuel consumption or rising fuel prices. They do not have possibilities to change fuel prices but they have opportunities to procure new technologies increasing vehicle operation efficiency, safety and environmental friendliness [8-12]. One of the aspects to increase this efficiency is to improve aerodynamic properties of the vehicle by purchasing and applying aerodynamic vehicle body devices. Therefore, more and more producers of aerodynamic devices are emerging in the market. Also, thanks to the global emissions reduction policy, the aim of which is to reduce the long-term trend of deteriorating conditions of the environment, companies are encouraged to increase the vehicle operation efficiency.

Directive (EU) 2015/719 amending Council Directive 96/53/EC also provides, among others things:

$\checkmark$ Better environmental performance;

$\checkmark$ Better road safety;

$\checkmark$ Benefits for carriers in terms of reducing fuel costs;

$\checkmark$ Industrial opportunity for vehicle manufacturers; and

$\checkmark$ More consistent controls and less damaged roads.

\section{THE BASICS OF AERODYNAMICS OF HEAVY DUTY VEHICLES}

It is obvious that a moving vehicle passes through the air that prevents it from moving. The airflows hit the frontal area and this creates a high 
pressure area on the vehicle frontal area [1]. The manufacturers of heavy-duty vehicles and body components of the vehicles cannot afford to reduce this vehicle frontal area because the priority of heavy-duty vehicles remains in transporting as many goods as possible. This fact requires large dimensions of the loading space which results in an enlarged vehicle frontal area [13]. Therefore, it is necessary to deal with the issue of reducing the air drag coefficient in order to reduce fuel consumption of heavy-duty vehicles.

Based on Fig. 1, it can be seen that heavy-duty vehicles (especially combination vehicles) have the highest coefficient of aerodynamic drag $\left(C_{D}\right)$ among road vehicles. At present, the value of this coefficient ranges from 0.55 to 0.65 (tarpaulin and body box vehicles).

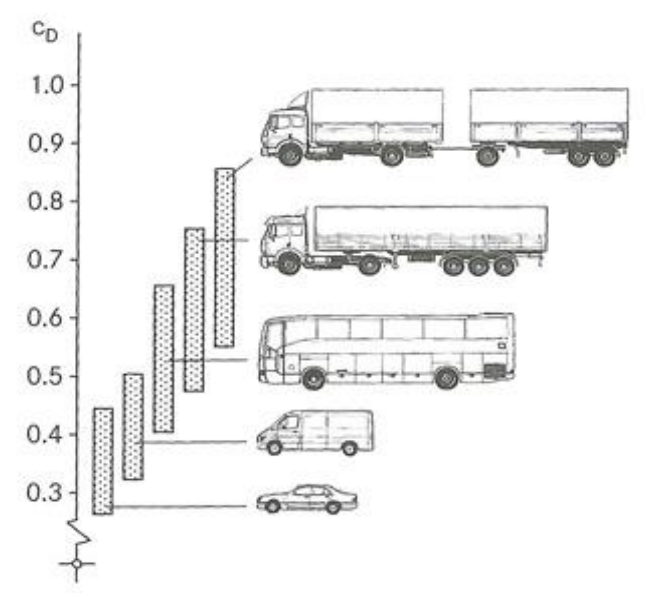

Fig.1. Coefficients of aerodynamic drag for selected vehicle categories [14]

To achieve good aerodynamic properties of a heavy duty vehicle, it is necessary to eliminate the high pressure areas of the vehicle body during the contact with the air and thus to ensure the smooth airflow along the entire perimeter of the vehicle. Mainly, there are four basic high pressure zones of the vehicle body, Fig. 2:

$\checkmark$ A vehicle frontal area;

$\checkmark$ Gap between a cab and semi-trailer;

$\checkmark$ A side and bottom part of the freight vehicle; and

$\checkmark$ A rear part of the freight vehicle.

Fig. 2 demonstrates that up to $75 \%$ of aerodynamic drag is related to a semi-trailer or trailer. Semi-trailer manufacturers are aware of this fact and therefore they strive to produce aerodynamic semi-trailers using components that improve aerodynamic features and thus reduce fuel consumption. This applies mainly to the roof and the rear part of heavy-duty vehicles (specifically in the area of the rear door). The example of an aerodynamic semi-trailer can be seen in Fig. 3, and trailer in Fig. 4.

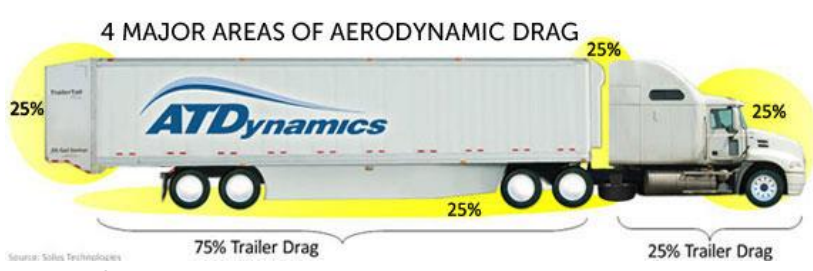

Fig.2. Zones of the most significant impact of aerodynamic drag on an articulated vehicle [15]

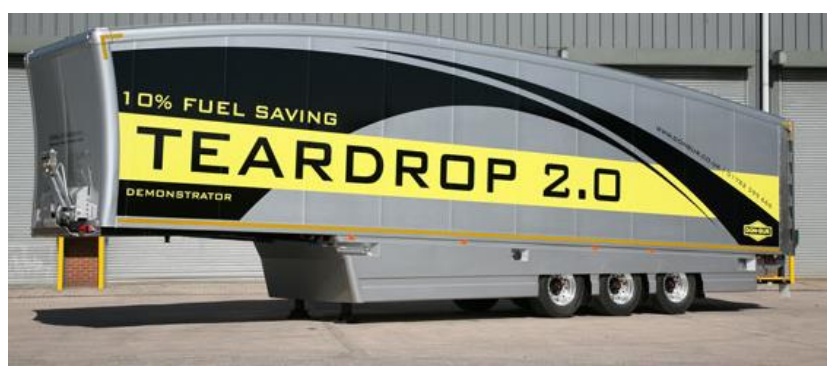

Fig.3. Aerodynamic semi-trailer [16]

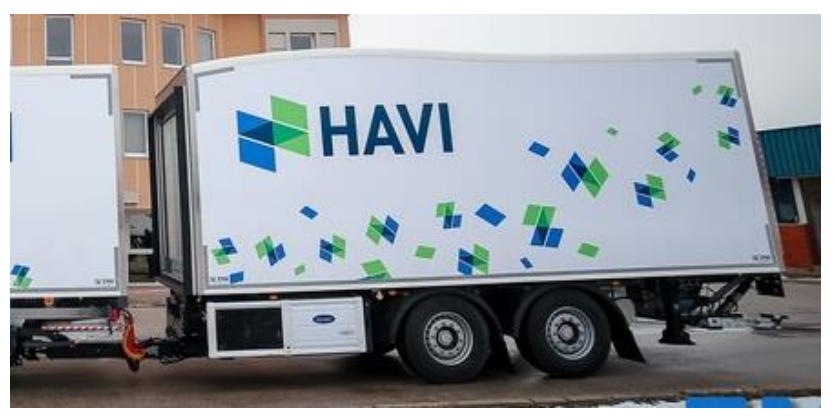

Fig.4. Aerodynamic trailer [17]

\section{VEHICLE BODY DEVICES REDUCING FUEL CONSUMPTION}

\subsection{Deflectors and roof fairing}

Deflectors are already commonly used components of a vehicle body. It is a cover mounted on the roof of the cab and it helps to the smooth airflow from the front to the rear part of the heavy-duty-vehicle, Fig. 5. Therefore, it is important that the cab part coincides with the front deflector part and the rear deflector part coincides with the semi-trailer roof. It is appropriate to eliminate the gap between the cab and semitrailer if the structure allows. If the deflector did not coincide with other surfaces to which it is fixed (e.g. it would be larger or smaller), the coefficient of aerodynamic drag would increase resulting in the elimination of deflector advantages. The removal of this part has led to increases in fuel efficiency. 


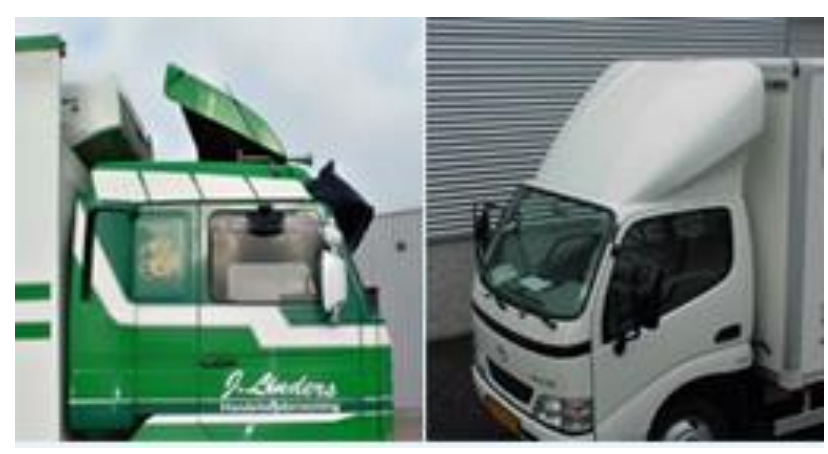

Fig.5. 2D deflector on the left (the old one-no longer used today) and 3D deflector on the right

\subsection{Front bumper}

The role of the front bumper is to prevent air from flowing underneath the vehicle. If the bottom vehicle part is flat, however, the front bumper may have the opposite effect on the vehicle aerodynamics. The friction force in the front part of the vehicle body increases and this causes higher aerodynamic drag.

In order to ensure smooth airflow around the vehicle, it is necessary to direct such airflow to the appropriate aerodynamic surfaces of the vehicle. The bumper should redirect the air to the side parts of the vehicle body and roof and thus the pressure on the vehicle frontal area is reduced. The shape of the front bumper also influences the flow of the air to the wheels. It is necessary to align the front bumper with other adjacent parts. Distribution of the air by the front bumper has a significant impact on vehicle behaviour and the airflow to other parts of the vehicle parts.

The example of modern aerodynamic bumper can be seen in Fig. 6 .

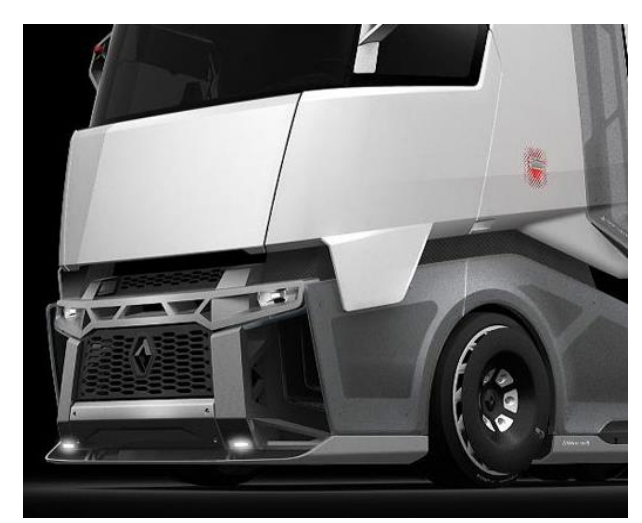

Fig.6. The front aerodynamic bumper of the Renault truck concept

\subsection{Windshield}

The windshields should be designed in such a way that ensures smooth connection of the vehicle hood and the roof. Ideally, the hood, windshield and roof should form one curved surface, Fig. 7 . Then, the air would flow smoothly from the front to rear part of the vehicle body. The windshield should be designed to minimize the pressure on the glass surface. This is achieved by increasing the angle between the windshield and the hood surface. This brings a problem with it. If the angle between the windshield and the hood surface increases, this results in lengthening the vehicle body and thus less visibility for the driver. Therefore, the attention can be drawn to transverse curvature of the glass. This is to result in the airflow directed to the vehicle body sides, less noise in the cab, smaller coefficient of aerodynamic drag and thus lower fuel consumption.

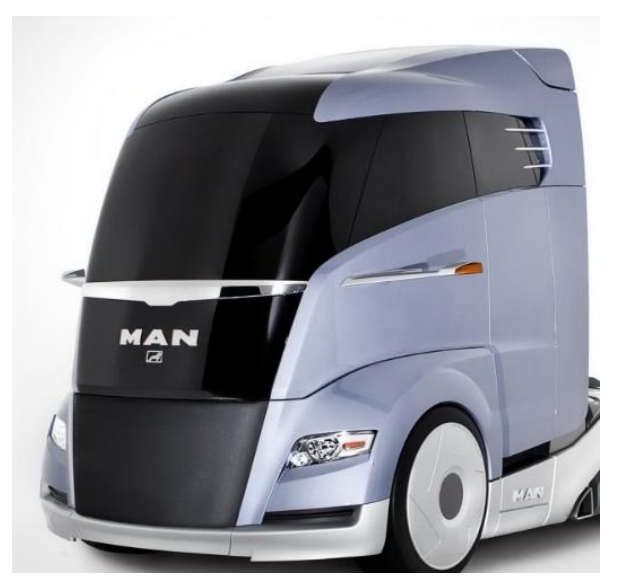

Fig.7. Curved windshield of the truck concept of MAN manufacturer

\subsection{Sun visor}

A sun visor can be mounted onto the heavyduty-vehicle body within the windshield. Primarily, the sun visor is designed to prevent the driver from dazzle. However, if such a sun visor is also properly aerodynamically designed (with curved edges), it can fulfil an aerodynamic function by directing the airflow and reducing the resistance of the cab and roof edges. Fuel saving of $3 \%$ can be achieved by such mounting.

\subsection{Exterior side mirrors}

Unlike passenger cars, heavy-duty vehicles and combination vehicles are equipped with side mirrors of much larger dimensions for good visibility. Side mirors, both increase the frontal area of the vehicle and increase the coefficient of drag. These larger dimensions result in the increased air resistance. Therefore, it is necessary 
to pay attention to the aerodynamic shape of this important component.

In addition to proper airflow, the proper drainage of rainwater must be also taken into account when designing side mirrors. At present, cameras are being tested as a replacement for side mirrors. Removing these mirrors would reduce fuel consumption. The camera system with infrared technology would provide the driver with good visibility even during snowfall, fog and rain. In addition to aerodynamics, the result would also consist in the improved road safety given to better visibility.

\subsection{Bottom, chassis and axles}

The bottom part of the vehicle may affect the coefficient of aerodynamic drag. If the bottom part is not flat (with protruding parts of the chassis), it may result in the increased coefficient of aerodynamic drag. Therefore, a flat surface is ideal and it can be achieved by various covers of chassis parts. The impact of such covers multiplies if the vehicle does not have a sufficiently large front bumper, side covers and it has a high ground clearance. Underneath the vehicle, excessive amount of the air and also side wind then arise. An overpressure zone occurs underneath the vehicle. This phenomenon causes the vehicle to become lighter. However, this phenomenon has no major impact on driveability due to the heavy weight of freight vehicles.

\subsection{Cab vanes}

Cab side vanes are used to extend the cab. Such extension is necessary in the case of a large gap between the cab and box body or semi-trailer (loading space). The air then flows into this gap and the side wind is also an adverse event in this case. These phenomena cause "pushing off" the semi-trailer away from the tractor and this result in the occurrence of overpressure zone and increase in fuel consumption. Therefore, the use of cab vanes decreases the coefficient of aerodynamic drag and reduction in fuel consumption by $0.7 \%$. When assembling cab vanes, however, it is necessary to ensure that cab vanes do not interfere with the radius of rotation of the outer edge of the semi-trailer. Because of this issue, the rubber is attached to the drain edges of vanes in order to minimize the difference between the cab and semi-trailer.

\subsection{Wheel covers and aerodynamic mudflaps}

Wheel covers are one of the fastest and easiest ways to fuel savings. They are not financially demanding and they are well available for carriers. Such wheel covers can ensure fuel savings because they reduce the vortices resulting from the air flowing from the front vehicle part to the rotating wheels. The use of wheel covers limits the entry of dirt and other exterior influences into the wheel space and thus reduces the losses, Fig. 8. However, the disadvantage of these components consists in insufficient cooling of the brakes. If manufacturers do not offer technology for cooling the brakes, the use of aerodynamic wheel covers will remain limited.

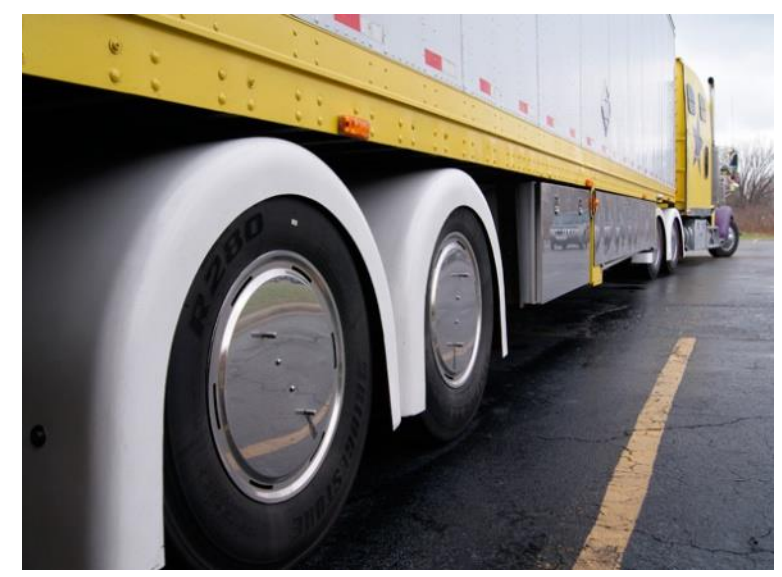

Fig.8. Wheel covers [18]

Aerodynamic mudflaps are used to catch dirt. Thus, the vehicle bottom part is protected from dirt thrown up by wheels. However, aerodynamic mudflaps also catch the air flowing in the bottom part of the vehicle body. The effect aerodynamic mudflaps is multiplied in the rear part of freight vehicles where the aerodynamic mudflaps are used extended along the width the vehicle. Their surface can also be used for advertising purposes. Carriers have also options to use the aerodynamic mudflaps which allow better passage of air through them. Such aerodynamic mudflaps can save fuel consumption by $3.5 \%$.

\subsection{Rear deflector and side skirts}

A rear deflector (boat tail) can achieve good aerodynamic properties by directing the airflow in the rear part of the semi-trailer resulting in reduction of vortices in the back of the articulated vehicle or solo freight vehicle, Fig. 9. 


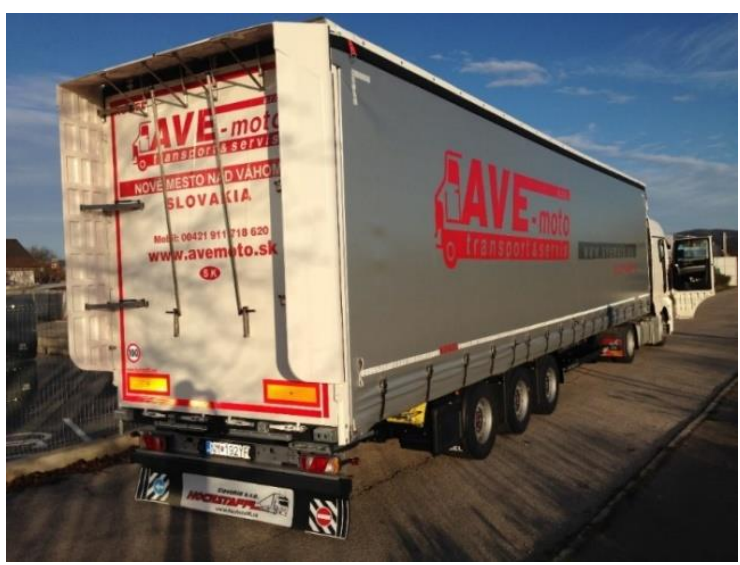

Fig.9. Rear deflector (boat tail) [19]

In the case of an articulated vehicle (combination of a tractor and semi-trailer), the rear deflector provably reduces aerodynamic drag during driving on flat road at "limited" speed of $90 \mathrm{~km} \cdot \mathrm{h}^{-1}$ by about $2 \%$, side skirts reduce the drag by $3.4 \%$, and their combination, Fig. 10 by $6.5 \%$ [20]. This does not represent an expression of the impact on fuel consumption but it expresses the reduction in driving resistance. However, the mentioned numbers are proven, what cannot be always said in terms of producer marketing activities of these components.

Currently, fuel consumption measurements using these components are being carried out by an expert team of Department of Road and Urban Transport at the University of Žilina and the final results will be presented after measurement final completion, Table 1.

Table 1. Result of fuel consumption savings [19]

\begin{tabular}{|c|c|c|c|c|c|}
\hline Mode & $\begin{array}{c}\mathrm{LW} \\
{[\mathrm{t}]}\end{array}$ & $\begin{array}{c}\text { Temp. } \\
{[\mathrm{C}]}\end{array}$ & $\begin{array}{c}\text { FC savings } \\
{[\mathrm{l} / 100 \mathrm{~km}]}\end{array}$ & $\begin{array}{c}\text { Av. } \\
\text { Veh. } \\
\text { Velocity } \\
{[\mathrm{km} / \mathrm{h}]}\end{array}$ & $\begin{array}{c}\text { Av. Acc. } \\
\text { Positioning } \\
{[\%]}\end{array}$ \\
\hline Uphill & 7.95 & 19 & 0.5 & 77 & 24.5 \\
\hline Downhill & 5.35 & 19 & 0.8 & 77 & 23.5 \\
\hline
\end{tabular}

(LW -load weight; Temp. -temperature; FC -fuel consumption; Av. Veh. Velocity -average vehicle velocity; and Av. Acc. Positioning-average accelerator positioning)

The provisional results are known for now - fuel consumption decreasing at the level of $0.5-$ $0.8(\mathrm{l} / 100 \mathrm{~km})$ from the fuel consumption of $26.5(\mathrm{l} / 100 \mathrm{~km})$ by using the rear deflector. This value depends on more operation factors like actual vehicle weight, average vehicle velocity, or average road slope [19].

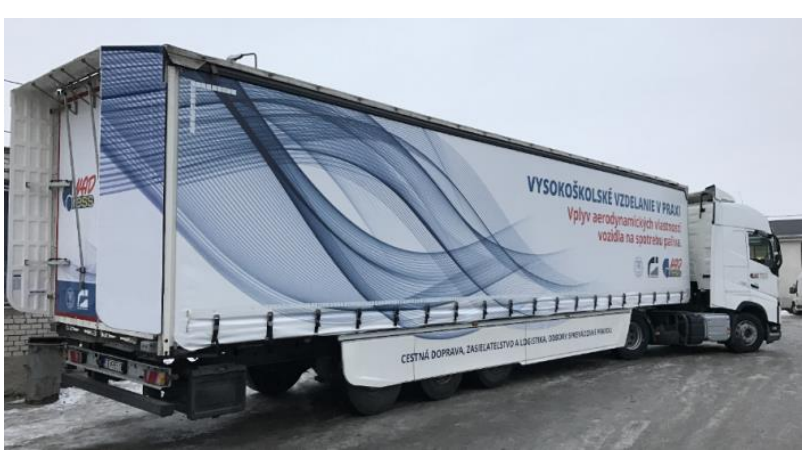

Fig.10. Combination of the rear deflector (boat tail) and side skirts (test trailer of University of Žilina)

\section{REAR DEFLECTOR IN A NEW TECHNOLOGICAL SOLUTION}

Plasma stream technology uses the system of an active flow control system which utilizes plasma actuators, Fig. 11. The system was developed at the University of Notre Dame. The system is capable to generate a force field which controls airflow separation from the vehicle body. By controlling the separation of airflow and its directing, the resistive force of the air flowing around the moving vehicle is reduced, Fig. 12 and Fig. 13.

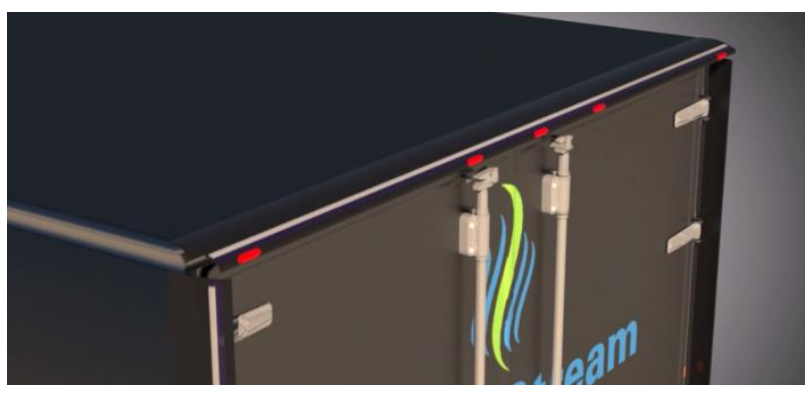

Fig.11. Plasma Stream actuators [21]

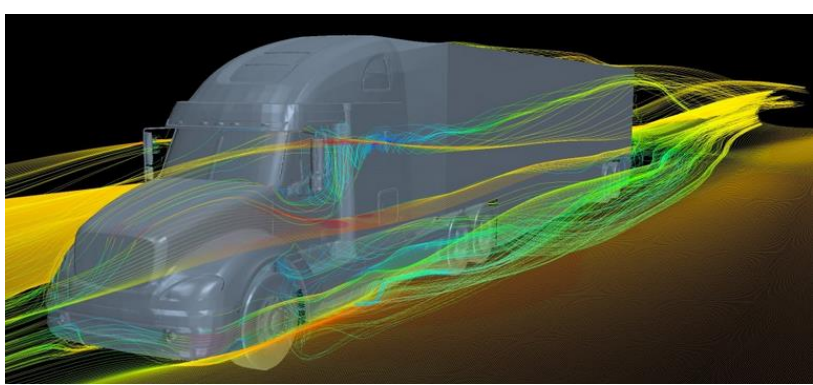

Fig.12. New technological solution of the rear deflector [21]

In principle, this technology can be applied to every vehicle regardless of its shape and dimensions. Thus, it is not a technology that can be used only for freight vehicles of the selected superstructures as in the case of deflectors. 

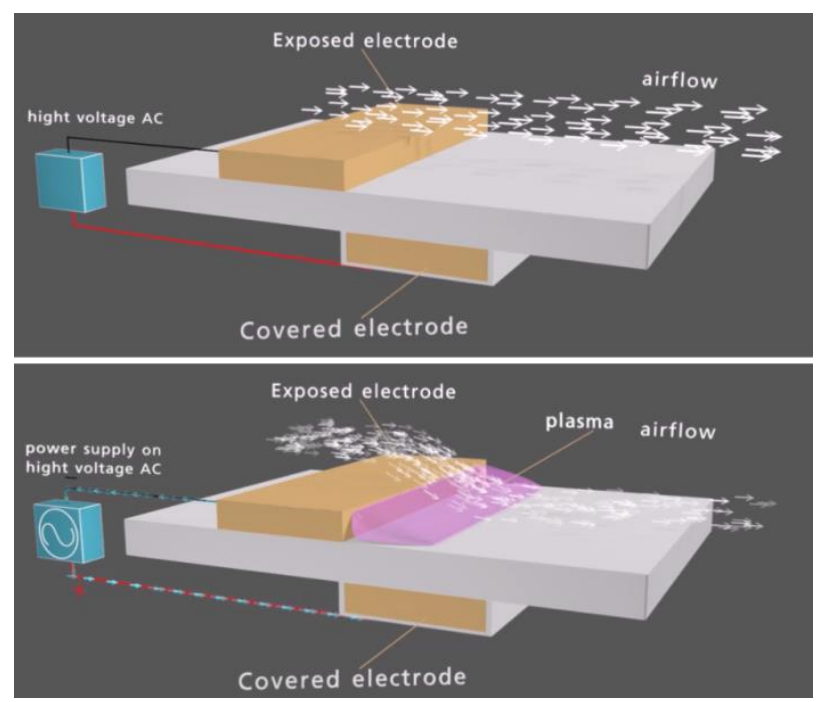

Fig.13. Plasma Stream technology principle [21]

Physical devices such as spoilers, deflectors, covers, panels are designed to guide the airflows in a precisely defined direction. Plasma actuators are capable to do so by ionizing the airflow without the added structural components or weight, Fig. 14. Even the best designed physical aerodynamic devices attempt to divert the airflow, unlike the plasma that modifies the existing flow field.
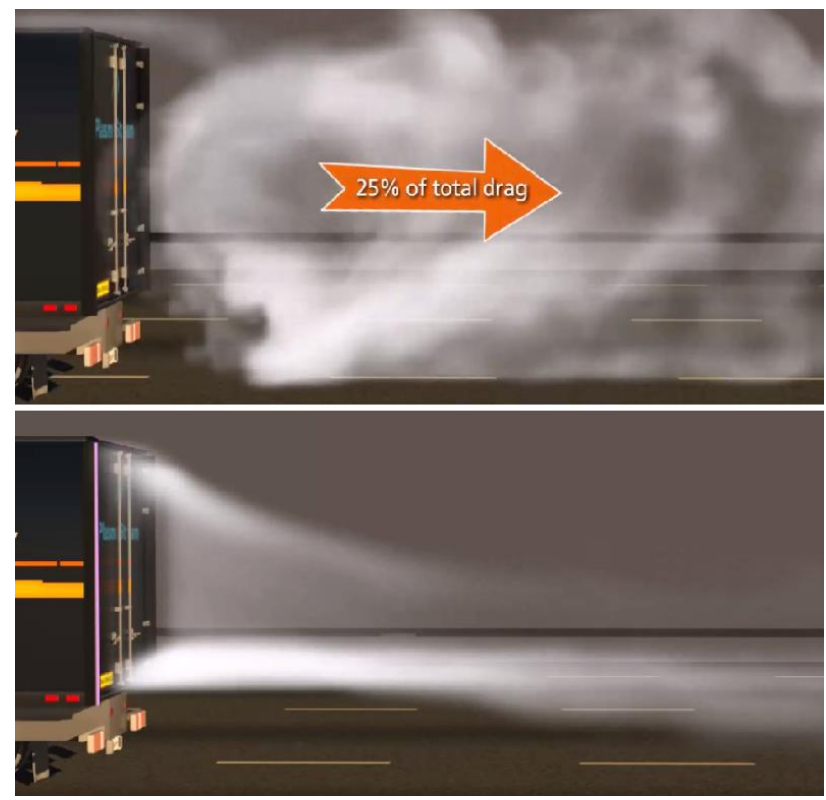

Fig.14. Effect of Plasma Stream technology [21]

The big advantage is that the technology can be used for all surfaces and edges of the vehicle body and thus it could also be used in the future to divert the airflow around rotating wheels, side mirrors and other "exposed" elements creating air vortices.

Given the necessary power input to create a plasma force field, however, it is questionable to what extent the vehicle operation will be actually more efficient as Plasma Stream system obtains the energy from the vehicle battery which is charged by the alternator that inevitably takes more power from the engine resulting in increased fuel consumption. Therefore, the actual effect of the device will depend on the difference between fuel consumption savings by reducing aerodynamic drag and fuel consumption increase due to generation of electrical power consumed by plasma. The data regarding necessary power input to create plasma has not been provided so far. The producer of the technology only indicates reduction in fuel consumption by $7-10 \%$, however, information related to vehicle operation regime or speed at which the mentioned result was ascertain is not available. As the technology is produced by an American producer, the speed of $65 \mathrm{mph}\left(105 \mathrm{~km} \cdot \mathrm{h}^{-1}\right)$ can be considered. But, this speed cannot be taken into account in the case of Europe. At lower speed, the impact of air resistance is lower and therefore lowers fuel savings can probably be considered compared to data provided by the producer.

\section{CONCLUSIONS}

The reduction of drag in road vehicles has led to increases in the top speed of the vehicle and the vehicle's fuel efficiency, as well as many other performance characteristics, such as handling and acceleration.

Bodies of heavy-duty vehicles (especially combination vehicles) have a higher coefficient of drag than passenger cars due to their dimensions and shape. Up to $75 \%$ of aerodynamic drag is related to a semi-trailer or trailer.

There are many different ways to reduce the drag of a vehicle. A common way to measure the drag of the vehicle is through the drag area.

As technology for reducing air drag of semitrailers, is analysed here optimized construction of rear deflector with Plasma Stream technology.

\section{REFERENCES}

[1] T. Skrucany, M. Vojtek, G. Šuchter, Fixation of tarpaulin sheet of platform HDV and its impact to air resistance. Transport technic and technology, 12(1), 2018: 6-10. https://doi.org/10.2478/ttt-2018-0002

[2] J. Lizbetin, M. Hlatka, L. Bartuska, Issues concerning declared energy consumption and greenhouse gas emissions of FAME biofuels. Sustainability, 10(9), 2018: 3025. 
https://doi.org/10.3390/su10093025

[3] J. Lizbetin, O. Stopka, F. Nemec, Methodological Assessment of Environmental Indicators in Combined Transport in Comparison with Direct Road Freight Transport, $20^{\text {th }}$ international scientific conference Transport means 2016, Kaunas, Lithuania, 2016, pp.151-155.

[4] M. Škorupa, T. Čechovič, M. Kendra, B. Jereb, Case study of the impact of the $\mathrm{CO}_{2}$ emissions trend from transport on the external costs in slovakia and slovenia. Transport technic and technology, 12(2), 2018: 23-27.

https://doi.org/10.2478/ttt-2018-0007

[5] B. Šarkan, J. Caban, A. Marczuk, J. Vrábel, J. Gnap, Composition of exhaust gases of spark ignition engines under conditions of periodic inspection of vehicles in Slovakia $=$ Skład spalin z silników o zapłonie iskrowym w warunkach okresowych badań pojazdów na Słowacji. Przemysl Chemiczny, 96(3), 2017: 675-680.

https://doi.org/10.15199/62.2017.3.36

[6] S. Milojevic, Optimization of the Hydrogen System for City Busses with Respect to the Traffic Safety, $20^{\text {th }}$ World Hydrogen Energy Conference (WHEC 2014), 15 ${ }^{\text {th }}$ June 2014, Gwangju, South Korea, pp.853-860.

[7] S. Milojević, Sustainable application of natural gas as engine fuel in city buses - Benefit and restrictions. Journal of Applied Engineering Science, 15(1), 2017: 81-88.

https://doi.org/10.5937/jaes15-12268

[8] S. Milojević, T. Skrucany, H. Milošević, D. Stanojević, M. Pantić, B. Stojanović, Alternative Drive Systems and Environmentaly Friendly Public Passengers Transport. Applied Engineering Letters, 3(3), 2018: 105-113.

https://doi.org/10.18485/aeletters.2018.3.3.4

[9] A. Lebkowski, Studies of Energy Consumption by a City Bus Powered by a Hybrid Energy Storage System in Variable Road Conditions. Energies, 12(5), 2019: 951. https://doi.org/10.3390/en12050951

[10] M. Jurkovic, T. Kalina, A. F. Teixeira, Possibilities of using alternative fuels for transport solution in Brazil, $21^{\text {st }}$ international scientific conference Transport means 2017, Kaunas, Lithuania, 2017, pp. 724-72.

[11] D. Barta, M. Mruzek, M. Kendra, P. Kordos, L. Krzywonos, Using of Non-Conventional Fuels in Hybrid Vehicle Drives. Advances in Science and Technology Research Journal, 10(32), 2016: 240-247.

https://doi.org/10.12913/22998624/65108

[12] C. Csiszár, D. Földes, System Model for Autonomous Road Freight Transportation. Promet - Traffic \& Transportation, 30(1), 2018: 97-103.

https://doi.org/10.7307/ptt.v30i1.2566

[13] A. Polcar, J. Cupera, V. Kumbar, Calibration and its use in measuring fuel consumption with the can-bus network. Acta Universitatis Agriculturae et Silviculturae Mendelianae Brunensis, 64(2), 2016: 503-507. https://doi.org/10.11118/actaun201664020503

[14] J.Y. Wong, Theory of ground vehicles. John Wiley\&Sons. Inc., Ottawa, 2001.

[15] www.atdynamics.com (Accessed 13.04.2019.).

[16] http://www.donbur.co.uk/gben/products/aerodynamic-teardroptrailer.php (Accessed 13.04.2019.).

[17] http://www.ema-knic.com/services/vucnivozovi/, (Accessed 26.04.2019.).

[18] https://www.realwheels.com/aerodynamicwheel-covers/, (Accessed 13.04.2019.).

[19] T. Skrucany, J Čupera, T. Figlus, B. Abramović, C. Cziszár, Influence of Vehicle Aerodynamical Devices on Fuel Consumption Evaluated Using Telematics Tools, $8^{\text {th }}$ International Scientific Conference CMDTUR 2018, October 2018, Žilina, Slovakia, pp. 384-392.

[20] T. Skrucany, B. Sarkan, J. Gnap, Influence of Aerodynamic Trailer Devices on Drag Reduction Measured in a Wind Tunnel. Eksploatacja i Niezawodnosc - Maintenance and Reliability, 18 (1), 2016: 151-154. http://dx.doi.org/10.17531/ein.2016.1.20

[21] www.plasmastreamtech.com (Accessed 13.04.2019.). 